\title{
Augmented and Mixed Reality in Language Learning
}

\section{Panagiotis Panagiotidis}

\section{Abstract}

The use of Extended Reality technologies in education, and especially in language learning, has attracted the interest of language experts for the last 15 years. However, the recent technological progress as well as the simultaneous dramatic reduction of the cost of the necessary hardware has led to an impressive growth of the XR market, creating, thus, new perspectives concerning the adoption of XR technologies in education. The educational XR market is also growing very fast, not only thanks to the offer of innovative applications, but also due to technological developments in network technologies. Advances in wireless and cellular networks can make XR experiences more immersive and more accessible to local and remote users. This paper aims to present the current developments in the field of utilization of Augmented (AR) and Mixed Reality (MR) technologies in language education and to explore their future perspectives. Towards this end, AR/MR technologies, the theoretical bases of their use in language education, as well as the available for each technology hardware and software solutions are presented in more detail. Examples of AR/MR technologies in language learning applications, as well as the conclusions drawn from the literature review concerning the benefits and limitations $\mathrm{AR} / \mathrm{MR}$ applications in language learning will also be presented. Finally, market data and future research directions will be discussed, in order to identify the perspectives of these technologies in language learning.

Keywords: extended reality, augmented reality, mixed reality, immersive technologies, language learning, motivation

\section{Introduction}

The term "Extended Reality" (XR) is an umbrella term that covers a variety of simulation-based technologies such as Augmented Reality (AR), Virtual Reality (VR), Mixed Reality (MR) and Holography (HG) that either blend the physical environment with the virtual or are able to provide fully immersive virtual experiences (Pomerantz, 2019). In order to describe the full spectrum of these technologies, Milgram \& Kishino proposed quite early, in 1994, a "virtuality continuum" that spans between an entirely real environment -the physical world-, and an entirely virtual computer-generated environment. The various technologies described by the general 
term XR, can be placed on this "real-to-synthetic" axis, depending on the environment they create for the user, the equipment in use, the degree of immersion they allow, and the interaction they offer with the environment.

The two most important and, at the same time, distinct technologies are AR and VR. AR refers to the real-time combination of digital and physical information by overlaying physical objects and places with virtual content), while VR creates a complete, artificial, virtual environment (Hein et al, 2021).

Implementation of XR technologies in education is not new. During the last two decades, XR technologies have been tested in several subjects, including language learning. However, technological progress and more specifically the huge increase in computing power, advances in graphics and display technologies that are necessary for the creation of appropriate immersion systems, the evolution of mobile devices and technologies, as well as the simultaneous dramatic reduction of the cost of the necessary hardware, create new perspectives concerning the adoption of XR technologies in education.

According to the Horizon Reports of the last 4 years, XR technologies are among the most important technologies that will generally be adopted in education in the very near future (Adams Becker et al, 2017; Adams Becker et al, 2018; Alexander et al, 2019; Brown et al, 2020).

In this paper, the theoretical bases of Augmented and Mixed Reality use in language education, as well as the available for its technology hardware and software solutions, are presented in more detail. Examples of AR/MR applications, as well as the conclusions drawn from literature review concerning the benefits and limitations of their exploitation in language learning, will also be discussed.

\section{Theoretical background}

AR/MR applications are usually trying to adopt a game-based approach, in order to offer users a useful learning environment and, at the same time, the motivation to use it. Gamification, or as Kapp (2012:10) describes it “...using game-based mechanics, aesthetics and game thinking to engage people, motivate action, and promote learning", is not a novelty in language education. However, AR/MR applications, in combination with advances in mobile technologies, offer new possibilities in language learning (Holden \& Sykes, 2011; Dunleavy \& Dede, 2014; Ibrahim et al, 2018). Sydorenko et al (2019) believe that digital games, especially designed to fit the conceptualization of a task, may provide useful environments for social interaction and language learning.

AR applications are obviously based on pedagogical theories such as mobile learning, informal learning, game-based learning and also task/project-based learning can also support self-learning in everyday contexts. According to Dunleavy \& Dede (2014), 
situated learning and constructivist learning theories are the two evident theoretical foundations for AR technology.

Khoshnevisan \& Le (2018) as well as Hadid et al (2019) believe that AR can facilitate multimedia learning as it creates an interactive learning environment in which learners can better understand the real world with the presence of multimedia helping as scaffolding, background knowledge activator, motivator, and facilitator. AR enhanced environments, with the aid of superimposed materials, can provide learners with experiences that are similar to real life. Furthermore, AR is a suitable technology for contextual learning because it can be used to contribute contextspecific, just-in-time information in an interactive manner.

According to Godwin-Jones, R. (2016), there is an obvious connection between AR and current theories of second language acquisition which emphasize localized, contextual learning and meaningful connections to the real world. Parmaxi \& Demetriou (2020) have also arrived in conclusions concerning the theoretical and pedagogical support of the AR applications dataset in their research. They found that the sociocultural (9\%), situated (9\%), experiential (5\%) and constructivist $(5 \%)$ learning theories, which are all closely linked to the learning-by-doing paradigm, seem to gain researchers' interest. However, they also noted that the majority of the studies under investigation are left with no theoretical grounding (46\%).

\section{Augmented Reality (AR)}

Unlike VR, which creates a completely isolated synthetic environment, AR technology enhances the existing real world by adding digital objects to it in ways that make users believe those objects actually exist. Several researchers in the field, such as Azuma et al (2001), Klopfer \& Squire (2008), Yang \& Liao (2014), and Blyth (2018) have proposed definitions for AR. A commonly accepted definition of AR is that of Azuma (1997) who defined AR as an emerging technology that allows computergenerated virtual imagery information to be superimposed onto a live direct or indirect real-world environment in real time. Carmigniani et al (2011:342) define AR as "...a real-time direct or indirect view of a physical real-world environment that has been enhanced / augmented by adding virtual computer-generated information to it". Other researchers also consider that AR technology is augmenting the sense of reality and can be thought of as a bridge between the virtual and the real world (Solak \& Cakir, 2015; Lee, 2012). In AR the environment is real but extended with virtual elements or information (text, image, video, sound, animation) superimposed upon, or composited with, the real world. It must be noted that those virtual objects are static overlays above the physical world and can be automatically superimposed in any real background such as objects, landscapes, or books, without the need for an action /intervention of the user (i.e., by clicking). 


\section{AR hardware \& software}

AR can be experienced via advanced HMDs such as the Microsoft Hololens or smartglasses such as the -now discontinued- Google Glasses. However, most AR applications are designed to run on mobile devices that go wherever the user goes. The majority of studies support that mobile devices are considered the ideal platform for AR applications (Liu, Tan, \& Chu, 2007; Holden \& Sykes, 2011; Arvanitis, 2012; Liu \& Tsai, 2013; Khoshnevisan \& Le, 2018). The latest generation of smartphones disposes a vast range of mechanisms, sensors and technologies that makes them able to support XR applications: they have advanced user interfaces and can be operated by touch, gesture and voice, they are location-aware, thanks to inbuilt GPS receivers, and they have built-in compasses, gyroscopes and accelerometers, they support Bluetooth, RFID and NFC connections, they have all kind of input mechanisms such as cameras, microphones, OCR, QR codes and other augmented reality (AR) markers (Reinders \& Pegrum, 2016) as well as visual, auditory and haptic output modes (vibration). Thanks to these possibilities, today's mobile devices can help the user perceive the reality around him in a new way by the overlay of varied digital information (Ong, Shen, Zhang, \& A. 2011)

By viewing an object through a mobile device camera, the user is exposed to enhanced virtual layers placed over the real object. As soon as the user's camera points at the predefined trigger, namely an image or object, augmented media (e.g. video, 3D, and animation) are sent to the mobile device from an online database. Azuma (1997) believes that augmented reality is not limited to the sense of sight but might have application to the sense of sound as well. AR could be used to augment the sight of blind users or users with poor vision using audio cues, or augment hearing for deaf users using visual cues. Similarly, AR could be used to augment the sense of touch, using haptic sensors. Gloves with devices that provide tactile feedback could augment real forces in the environment.

There are currently two types of AR systems: Markerless and marker-based AR (Johnson et al, 2010; Lee, 2012). However, the terms location-aware or place-based AR and Vision or Image-based AR are also used in literature (Dunleavy \& Dede, 2014). Markerless or location-based AR applications use positional data, such as the GPS and the compass or image recognition, to determine the locations of its users and then guide them to a specific location. Once users reach the location, they can interact with superimposed elements such as images, videos or 3D objects and experience a reality augmented with resources, information, tasks, or prompts (Carmigniani et al., 2011; Thorne \& Hellermann, 2017). One of the most well-known location-based AR applications is the Pokemon Go, an AR game developed by NINTENDO in 2016, which detects players' locations and allows users to collect Pokemon monsters in different locations based on GPS sensor. Marker-based AR systems are based on image recognition and predefined markers as triggers to display AR content. Users must point the smartphone camera to perceive a specific visual cue to trigger AR actions. 
Once the device recognizes the marker, the AR app overlays the digital data on top of the augmented object.

AR can also be used to augment print media by superimposing 3D rendered models. Newspapers, magazines or books can be loaded with marker or trigger images that mobile devices with camera tracking AR applications can augment with audio, video, hyperlinks, images, social media feeds or HTML5 content from the web. In that case, printed material can be read normally, but if someone looks at the pages through a handheld AR display, they see three-dimensional models appearing out of the pages.

There are several SDKs (Software Development Kits) and platforms available for the development of AR applications. The most widely used are ARKit, Apple's SDK for iPhone and iPad, ARCore, Google's own SDK, Vuforia, which is one of the largest AR developer communities online today, Wikitude, which allows users to build augmented reality worlds on basis of HTML and JavaScript, ATOMIC Authoring Tool, a front-end for the open-source project ARtoolkitX, EasyAR, Lumin, Magic Leap's AR SDK for Unity, and Mixed Reality Toolkit (MRTK) for HoloLens and other Windowsbased Mixed Reality headsets. When it comes to language learning applications, a research carried out by Parmaxi \& Demetriou (2020) showed that Vuforia, ARIS (Augmented Reality and Interactive Storytelling) and HP Reveal (former Aurasma), gained researchers' preference for the development of mobile-based AR. ARIS is an open-source platform for creating GPS based AR enhanced learning games with storytelling structure, designed to be used by nonprogrammers, although customization and interactivity can be reached through HTML and JavaScript. ARIS is the platform used by several successful projects such as Mentira, Paris Occupé, ChronoOps and Hiroshima game (Perry, 2015; Godwin-Jones, 2016). HP Reveal / Aurasma, the most widespread AR platform with almost 100,000 global users and the most popular AR app among language educators, was shut down in 2020. This app used images or QR code (as triggers) and object recognition technology to activate AR content. In addition, it was possible to use a geographical location to create triggers from physical objects.

There are also several other AR platforms available which are potentially exploitable for educators as they allow users to select and design their own triggers and augmented overlays. Layar is based on printed materials and uses the GPS location to show what is nearby by displaying real time information on top of the image on the mobile's camera. Blippar lets users look at real-world objects enhanced with text, music, games and digital graphics through their smartphone camera and is also a platform that allows you to create and publish AR. ZooBurst is another popular educational digital storytelling tool, as it is designed to let anyone create their own augmented reality 3D pop-up books easily (Mahadzir \& Phung, 2013). Other systems are buildAr, TaleBlazer, Actionbound and Arloopa, which is recently gaining popularity as the successor of Aurasma. 


\section{Examples of AR applications}

Several studies have proposed the development of AR systems to improve language learning. In 2004, Ogata, Akamatsu \& Yano (2005) developed TANGO, a system capable of detecting objects around learners and provide object-related language learning materials by RFID technology. In 2007, Liu et al (2007) created HELLO, a 2D barcode, handheld, AR-supported English learning environment, aiming to enhance students' language skills. HELLO was part of the "My Campus" course and consisted of an English learning management system and a mobile learning tool. The evaluation results showed that HELLO and the proposed learning activities could increase students' motivation to learn, provide enjoyable and effective English learning experiences, and improve the students' English listening and speaking skills Liu et al, 2008). Two years later, Holden \& Sykes (2011) presented Mentira, the first AR placebased game for foreign language learning. Mentira was developed at the University of Wisconsin-Madison for Spanish language courses using the open-source ARIS platform. Results showed that playing the game increased students' motivation and awareness of pragmatic issues in Spanish. Perry (2015), inspired by Mentira, used ARIS to create Explorez, a place-based game directed towards the acquisition of French language skills. Explorez transforms the University of Victoria, B.C. campus into a virtual francophone world where students improve their French language skills by interacting with characters, items, and media in their quest through the campus. Another example of a place-based game is Paris Occupé, a series of role-playing (RPG) games, which allows learners to experience a simulation of life in Nazi-occupied Paris in the French language (Blyth, 2018). It is also worth mentioning LangAR, a foreign language phrasebook based on wikitude, developed in 2013 by the Future Technologies group at Pearson, to promote real-time contextualized vocabulary learning (Godwin-Jones, 2016), and ChronoOps, a quest-type mobile place-based AR game, which is currently available in seven languages (Thorne, \& Hellermann, 2017). The global success of Pokémon GO has inspired language experts, who found different aspects of the game suitable for language learning (Schrock, 2016). A similar concept is adopted by ImparApp, a location-based mobile game developed in Coventry University with MIT's game-authoring tool TaleBlazer, to offer tasks and challenges in Italian language (Cervi-Wilson \& Brick, 2018)

Several AR language learning studies were based on the very popular apps AURASMA / HP Reveal. Scrivner et al (2016) developed a beginner's level Spanish course, Taskiran, (2018) designed four different games to promote learners' skills in English, Yang \& Mei (2018) created an AR-based animation guide to help their students learn Japanese orthography with their mobile devices, and Allagui, (2019) used HP Reveal to facilitate EFL students' writing performance.

Many AR applications have been developed to investigate the promotion of all language skills. Parmaxi \& Demetriou (2020) found that vocabulary represents the most investigated topic area $(23.9 \%)$, followed by reading $(12.7 \%)$, speaking $(9.9 \%)$ 
and writing $(8.5 \%)$, whilst a substantial number of manuscripts focused on generic language skills (9.9\%). Liu \& Tsai (2013) designed AR-based mobile learning material about scenic spots to provide linguistic and content knowledge in English composition for the participants. Seedhouse et al (2014) created the marker-based app "European Digital Kitchen project" which allows learners to collaborate in English language learning tasks. Dalim et al (2016) created TeachAR, an AR tool which uses Microsoft Kinect's speech recognition to teach basic English words (colors, shapes, and prepositions) to children for whom English is not a native language. TeachAR was developed using the Unity game with the ARToolkit for Unity plugin and is also available in a non-AR version which works with mouse clicks. Dita (2016) proposed an AR app that uses the camera of the mobile device and text recognition to identify written texts. Krystalli et al (2020) used Blippar to develop an AR app based on augmented Greek buildings and spaces of cultural interest for the improvement of speaking skills and the pronunciation of students in the French language. Draxler et al (2020) developed an AR app for the learning of gram $\urcorner$ mar through dynamically created quizzes based on real-life objects in the learner's surroundings. Agata et al (2021) used Unity with the addition tool Vuforia SDK to create an Android AR app with learning media and English quizzes based on the "Thematic English Learning 1" book to enrich students vocabulary.

Another implementation of AR technology which is becoming more and more popular is Enhanced textbooks, or 3D pop-up books. Zooburst is an educational digital storytelling tool, frequently used for such interactive books (Mahadzir, \& Phung, 2013). Hadid et al (2019) developed "Reader Buddy", an app which uses triggers or QR codes to augment textbooks. Finally, several applications covering other aspects of language learning such as TranslatAR, a mobile AR translator, have also been developed (Fragoso et al, 2011).

\section{Mixed Reality (MR)}

There is not a clear definition for mixed reality, as the term is used to cover all extended reality applications that, as mentioned earlier, are lying somewhere on the con ᄀtinuum between AR and VR. Hein et al (2021) define MR as the human-machine interactions generated by computer technology and wearables in combined real and virtual environments. AR and MR systems have the ability to alter human perception as they both augment the real world with virtual objects. The difference is that augmented reality takes place in the real world, while mixed reality is a blend of physical and digital worlds and produces new environments and visualizations, where physical and digital objects co-exist and interact in real time. MR systems may allow users to interact with these objects (Leonard, \& Fitzgerald, 2018; Parsons et al, 2019; Al-Gindy et al, 2020). Pomerantz (2019) notes that users can affect the state and behavior of these virtual objects, and these virtual objects may also affect the state and behavior of physical objects. 


\section{MR hardware \& software}

HMDs, with the ability to project a computer-generated environment and, at the same time, a real-world camera view from integrated cameras. Common VR Headsets, such as Oculus Rift S (\$599) or HTC VIVE (\$799) are not suitable for Mixed Reality, as they do not dispose cameras. MR Headsets leave the natural world completely visible, allowing the user to move around while engaging with virtual and natural objects. Microsoft's Hololens 2 (\$3.500) is the most well-known commercially available Mixed Reality device. Hololens 2 is a holographic wearable computer with lenses that project holograms and allows users to interact with both real-world artefacts and virtual artefacts as though they existed in the physical surroundings. Hololens 2 allows for the user's movement in space and adjusts the image accordingly so that it appears to act like a real object (Leonard, \& Fitzgerald, 2018). The device offers hands free interaction using natural gestures and a more intuitive perception of the AR experience. Another very advanced MR Headset is the Magic Leap One (\$2299). ML1 headset is a wearable computer for enterprise productivity and can support 3D visualization and collaborative co-presence as well as concurrent web apps. Both devices are independent, stand-alone headsets and offer a high level of mobility but they have differences in terms of portability and freedom. The HoloLens 2 is heavier and bigger, as it keeps all the necessary equipment in the headset. The Magic Leap One keeps the computing separate in a portable pint-sized computer connected by a trailing cable. There are other options on the market, such as Varjo XR-3 (€5.495,00) and VR-3 $(€ 3,195,00)$ headsets which can deliver high-end results, but they need a powerful desktop computer to operate and therefore are not directly competitive with the aforementioned. MR headsets may offer new educational possibilities, not possible with virtual reality (VR) and AR technologies. However, they are much more expensive than VR headsets, and thus, their wider usage in real-classroom contexts seems limited.

\section{MR hardware \& software}

Mixed reality applications for language learning, are in their majority based on Microsoft Hololens 2. As this device can support both mixed and augmented reality some of the examples presented below could be considered relatives to augmented reality applications.

Based on the HoloLens 2, Leonard \& Fitzgerald (2018) developed an educational design research project in a secondary school setting in Australia. Both learners and teachers found the technolᄀogy engaging and promising, although some implementation issues, both technical and pedagogical, have been reported. Vazquez et al (2017) developed WordSense, a Mixed Reality platform designed to facilitate dynamic, markerless embedding of content on physical objects for vocabulary learning. The system was based on Hololens' depth-sensing capabilities, which allowed designers to seamlessly blend reality with content in order to achieve contextual affinity. Ibrahim et al (2018) developed Arbis, a Hololens based 
application for vocabulary learning and compared it to a traditional flashcard-based learning approach. Results showed that the immersive AR experience of learning with virtual labels on real-world objects was more effective and more enjoyable for the majority of participants, compared to flashcards. Rzayev et al (2020) developed a Hololens-based application that enables detecting text in the foreign language in the environment and displaying translation for these words. During the study, participants learned vocabulary in the foreign language while reading the words in the real world and viewing the translation on the specified positions using Hololens. Finally, Huynh et al (2019) developed a framework for improving in-situ learning paradigms. The system uses a client-server architecture that allows for real-time labelling of objects in a Hololens that automatically displays the concept(s) associated with an object in the target language and provide a method for both the viewing and selection of a particular term or concept.

\section{Benefits for language learning}

Several AR and MR applications, that cover a wide spectrum of hardware specifications, learning design, theoretical bases, and linguistic targets, have been presented in the previous paragraphs. There is a sense that the main target, in an important part of these studies, was the exploration of these new technological means, as a specific pedagogical approach is not easily recognizable. However, there is also a strong conclusion that AR and MR technologies offer several important benefits in language learning. These benefits could be classified in four categories:

Increased motivation, engagement, and participation enjoyment constitute the most widely reported category of benefits in the literature review. Several studies report students' increased motivation to engage with XR technologies and higher levels of interest and engagement in comparison to conventional teaching methods (Perry, 2015; Richardson, 2016; Godwin-Jones, 2016; Taskiran, 2019). AR technologies can also create playful and motivating multimedia training environments (Azuma (1997). Thorne, \& Hellermann (2017) believe that AR games increase engagement in the language learning process by moving students and language learning experiences out of the classroom and providing opportunities for communication and language use. Several other researchers found evidence of AR/MR leading to heightened levels of motivation, engagement, and interest (Scrivner et al, 2016; Akçayır \& Akçayır, 2017; Rafiq \& Hashim, 2018; Khoshnevisan \& Le, 2018).

Reduced anxiety is also a benefit that can be registered into this category. Alemi et al (2015) have pointed out that employing technology to assist language learning can reduce students' anxiety and foster their positive attitudes towards the course. Drawing attention (Solak \& Cakir, 2015; Jamrus \& Razali, 2019), increasing students' learning interest, concentration (Wu et al, 2013; Zhang et al, 2014) and helping students enjoy the learning process (Núñez et al, 2008; Solak \& Cakir, 2015) are also some additional benefits worth considering. 
The second category includes benefits concerning cultural awareness and language skills. AR applications, in some cases, focus on cultural understanding and awareness, as in the previously mentioned Mentira project on Spanish language and culture (Holden \& Sykes, 2011). According to Jamrus \& Razali (2019) AR can offer great benefits by offering students an augmented world that they never experienced before due to geographical and cultural differences. However, in AR applications there is usually a more specific linguistic aim. Khoshnevisan \& Le (2018) carried out a literature review in 19 papers concerning AR applications on language education. The majority of the studies explored the impact of AR on literacy and on vocabulary. Hein et al. (2021), as well as Parmaxi \& Demetriou (2020) in their literature review in integrating AR into language learning, recorded benefits for vocabulary acquisition, writing, reading, speaking, comprehension, pronunciation, and phonics. The most common applications seems to be those targeting at the enhancement or the acquisition of vocabulary. Draxler et al (2020) successfully used geo-location to en $\neg$ hance vocabulary learning, Hadid et al (2019) believe that AR make the acquisition of vocabulary easier than traditional methods and Solak \& Cakir (2015) found that AR had positive impact on increasing undergraduate students' motivation towards vocabulary learning in the language classroom. There is little or no study regarding the incorporation of AR in skills such as listening, speaking, and writing. However, Jamrus \& Razali (2019) mention the studies of Tobar-Munoz, Baldiris \& Fabregat (2017) on the use of AR for the development of reading comprehension and of Li, Guo, Zheng and Rau (2018) for the development of reading skills, and Parmaxi \& Demetriou (2020) the studies of Tang and Young (2014) for Chinese pronunciation and of Wang et al (2017) who used AR to improve a group of Chinese students' first language writing skills.

The third category includes benefits concerning general learning skills related to language learning. In their review Leonard, \& Fitzgerald (2018) found evidence that AR/MR applications lead to stronger interaction among students, between students and learning materials and between students and teach $\urcorner$ ers. Akçayır and Akçayır (2017), Yeh \& Tseng (2020) and Parmaxi \& Demetriou (2020) arrived at the same conclusion. Another finding deriving from literature review is that AR/MR technology makes learning more long lasting and effective (Solak \& Cakir, 2015) and leads to higher productivity and effectiveness in learning outcomes as compared to traditional learning methods (Ibrahim et al, 2018). Benefits such as decrease in cognitive load, improvement in long-term memory retention, collaboration (Leonard, \& Fitzgerald, 2018; Ibrahim et al, 2018), and development of learner confidence (Hadid et al, 2019) are also reported in AR/MR literature.

The last category of benefits refers to the 21st Century Skills (4Cs). Several researchers are convinced that XR technologies can enhance collaboration, creativity, communication, critical thinking and problem solving (Dunleavy et al, 2009; Rafiq \& Hashim, 2018; Scrivner et al, 2016) as well as students' multimodal literacy (Yeh \& Tseng, 2020). Several more studies conclude that AR/MR activities create 
opportunities for critical thinking, collaborative engagement and problem solving by providing location-specific information, prompts and use of multimedia elements (Thorne \& Hellermann, 2017; Holden \& Sykes, 2011; Perry, 2015).

The value of AR in language learning is undeniable, as they offer several benefits at cognitive, academic, and linguistic level. However, skepticism is also expressed. Cheng and Tsai (2013) as well as Khoshnevisan \& Le (2018) believe that the technical complexity of AR technology and the demanding learning tasks could lead to increased cognitive load and therefore to loss of motivation. Wu et al (2013) consider that students who apply AR in their learning may be cognitively overloaded by the large amount of information and the necessary simultaneous use of multiple technological devices. Dunleavy \& Dede (2014) also consider increased cognitive overload as a possibility that comes with AR use. Finally, Jamrus \& Razali (2019) fear that distraction from learning may be a problem, as the students may pay more attention to the virtual and augmented information rather than the real education content.

\section{Conclusion and future perspectives}

According to MarketWatch (2021, May 27) global demand for XR (VR, AR and MR) will grow by $45.0 \%$ to reach $\$ 346.39$ billion by 2026 . Global XR production was valued at $\$ 25.4$ billion in 2019 and is expected to grow by $46.5 \%$ annually over 2020 2026. The educational XR market is also growing very fast not only thanks to the offering of innovative applications but also due to technological developments in network technologies. Advances in wireless and cellular networks, such as Wi-Fi 6 (802.11ax) and 5G, will make XR experiences more immersive and more accessible to both local and remote learners.

As the cost of equipment decreases, the future of AR/MR technologies in education, and particularly in language learning, seems very promising. For some researchers, a future lighter and smaller "always-on" AR headset, capable of being worn and used all day, much like current smartphones, could be imagined (Ibrahim et al, 2018). Such an AR system could seamlessly provide the user with the foreign-language terms describing objects (or later possibly even processes) in their own physical environments. Huynh et al (2019) push the idea a step forward by imagining the combination of the system with vital sensors such as eye-trackers which can monitor the physical and mental state of the user, similar to the health sensors included in smartwatches. They argue that continuous monitoring of users' cognitive response when consuming educational content may provide the ability to gauge the user's current understanding of the foreign language. This information could be processed by a -future- machine learning classifier that could detect whether a user understands or is confused about a foreign word.

As research in both XR hardware and software is underway, similar attention should be paid to research on the pedagogical exploitation of these technologies. It is obvious 
that innovative instruction design is one of the main factors required for successful application in language education. AR/MR applications must adopt an inspired student-centered, instructional design, with emphasis to guided and collaborative interaction, and activities that combine formal and informal learning, in order to place students in meaningful, real-life situations.

It is certain that innovations such as these should be answered after implementation in real educational settings. Therefore, research and exploration of the vast potential of AR/MR technologies in language teaching and learning must be continued in order to create new learning opportunities and practical benefits for learners.

\section{References}

[1] Adams Becker, S. A., Brown, M., Dahlstrom, E., Davis, A., DePaul, K., Diaz, V., \& Pomerantz, J. (2018). NMC horizon report: 2018 higher education edition. Louisville, CO: Educause.

[2] Adams Becker, S., Cummins, M., Davis, A., Freeman, A., Giesinger Hall, C., Ananthanarayanan, V., Langley, K., and Wolfson, N. (2017). NMC Horizon Report: 2017 Library Edition. Austin, Texas: The New Media Consortium.

[3] Agata, D., Yuniarti, H., \& Adison, A. A. P. (2021, April). Android Based English Learning Media and Quiz Using Augmented Reality. In International Conference on Applied Science and Technology on Social Science (ICAST-SS 2020), 15-21. Atlantis Press.

[4] Akçayır, M. \& Akçayır, G. (2017) 'Advantages and challenges associated with augmented reality for education: a systematic review of the literature', Educational Research Review, vol. 20, 1-11. doi: 10.1016/j.edurev.2016.11.002.

[5] Alemi, M., Meghdari, A., \& Ghazisaedy, M. (2015). The impact of social robotics on L2 learners' anxiety and attitude in english vocabulary acquisition. International Journal of Social Robotics, 7(4), 523-535.

[6] Alexander, B., Ashford-Rowe, K., Barajas-Murph, N., Dobbin, G., Knott, J., McCormack, M., ... \& Weber, N. (2019). Horizon report 2019 higher education edition, 3-41.

[7] Al-Gindy, A., Felix, C., Ahmed, A., Matoug, A., \& Alkhidir, M. (2020). Virtual reality: Development of an integrated learning environment for education. International Journal of Information and Education Technology, 10(3), 171175.

[8] Allagui, B. (2019). Writing a descriptive paragraph using an Augmented Reality application: An evaluation of students' performance and attitudes. Technology, Knowledge and Learning, 1-24.

[9] Alsop, T. (2021, May 12). Top XR/AR/VR/MR applications in the education sector as per U.S. XR experts 2020. Statista, https://bit.ly/3vxR20F .

[10] Arvanitis, P. (2012). Augmented Reality in Language teaching and learning? In EDULEARN12 Proceedings-4th International Conference on Education and 
New Learning Technologies (IKEECONF-2015-312, Aristotle University of Thessaloniki), 2768-2772.

[11] Azuma, R., Baillot, Y., Behringer, R., Feiner, S., Julier, S., \& MacIntyre, B. (2001). Recent advances in augmented reality. IEEE computer graphics and applications, 21(6), 34-47.

[12] Azuma, R.T. (1997). A survey of augmented reality. Presence: Teleoperators and Virtual Environments, 6(4), 355- 385.

[13] Blyth, C. (2018). Immersive technologies and language learning. Foreign Language Annals, 51(1), 225-232.

[14] Brown, M., McCormack, M., Reeves, J., Brook, D. C., Grajek, S., Alexander, B. \& Weber, N. (2020). 2020 Educause Horizon Report Teaching and Learning Edition, 2-58. EDUCAUSE.

[15] Carmigniani, J., Furht, B., Anisetti, M., Ceravolo, P., Damiani, E., \& Ivkovic, M. (2011). Augmented reality technologies, systems, and applications. Multimedia tools and applications, 51(1), 341-377.

[16] Cervi-Wilson, T., \& Brick, B. (2018). ImparApp: Italian language learning with MIT's TaleBlazer mobile app. Innovative language teaching and learning at university: integrating informal learning into formal language education, 49.

[17] Cheng, K. H. \& Tsai, C. C. (2013). Affordances of augmented reality in science learning: sug $\neg$ gestions for future research. Journal of Science Education and Technology, 22(4), 449-462. doi:10.1007/s10956-012-9405-9.

[18] Dalim, C. S. C., Dey, A., Piumsomboon, T., Billinghurst, M., \& Sunar, S. (2016, September). TeachAR: An interactive augmented reality tool for teaching basic English to non-native children. In 2016 IEEE International Symposium on Mixed and Augmented Reality, 82-86. IEEE.

[19] Dita, F. A. (2016). A foreign language learning application using mobile augmented reality. Informatica Economica, 20(4), 76.

[20] Draxler, F., Labrie, A., Schmidt, A., \& Chuang, L. L. (2020, April). Augmented reality to enable users in learning case grammar from their real-world interactions. In Proceedings of the 2020 CHI Conference on Human Factors in Computing Systems, 1-12.

[21] Dunleavy, M., \& Dede, C. (2014). Augmented reality teaching and learning. In J.M. Spector et al. (Eds.). Handbook of Research on Educational Communications and Technology, 735-745. New York: Springer Science+Business Media.

[22] Dunleavy, M., Dede, C., \& Mitchell, R. (2009). Affordances and limitations of immersive participatory augmented reality simulations for teaching and learning. Journal of Science Education and Technology, 18(1), 7-22. doi:10.1007/s10956-008-9119-1.

[23] Fragoso, V., Gauglitz, S., Zamora, S., Kleban, J., \& Turk, M. (2011, January). TranslatAR: A mobile augmented reality translator. In 2011 IEEE Workshop on Applications of Computer Vision (WACV), 497-502. IEEE. 
[24] Godwin-Jones, R. (2016). Augmented reality and language learning: From annotated vocabulary to place-based mobile games. Language Learning \& Technology, 20(3), 9-19.

[25] Hadid, A., Mannion, P., \& Khoshnevisan, B. (2019). Augmented reality to the rescue of language learners. Florida Journal of Educational Research, 57(2), 81-89.

[26] Hein, R. M., Wienrich, C., \& Latoschik, M. E. (2021). A systematic review of foreign language learning with immersive technologies (2001-2020). AIMS Electronics and Electrical Engineering, 5(2), 117-145. https://bit.ly/3i7aQUz

[27] Holden, C. \& Sykes, J. (2011). Leveraging Mobile Games for Place-based Language Learning. International Journal of Game-Based Learning (IJGBL), $1(2), 1-18$.

[28] Huynh, B., Orlosky, J., \& Höllerer, T. (2019, March). In-situ labeling for augmented reality language learning. In 2019 IEEE Conference on Virtual Reality and 3D User Interfaces (VR), 1606-1611. IEEE.

[29] Ibrahim, A., Huynh, B., Downey, J., Höllerer, T., Chun, D., \& O'Donovan, J. (2018). Arbis pictus: A study of vocabulary learning with augmented reality. IEEE transactions on visualization and computer graphics, 24(11), 28672874.

[30] Jamrus, M. H. M., \& Razali, A. B. (2019). Augmented Reality in Teaching and Learning English Reading: Realities, Possibilities, and Limitations. IJARPED, 8(4), 724-737.

[31] Johnson, L., Levine, A., Smith, R., \& Stone, S. (2010). Simple augmented reality. The 2010 Horizon Report, 21-24. Austin, TX: The New Media Consortium.

[32] Kapp, K. (2012). The Gamification of Learning and Instruction: Game-Based Methods and Strategies for Training and Education. San Fransisco, CA: John Wiley \& Sons.

[33] Khoshnevisan, B., \& Le, N. (2018, April). Augmented reality in language education: a systematic literature review. In Proceedings of the global conference on education and research (GLOCER) conference, Vol. 2, 57-71.

[34] Klopfer, E., \& Squire, K. (2008). Environmental Detectives-the development of an augmented reality platform for environmental simulations. Educational technology research and development, 56(2), 203-228.

[35] Krystalli, P., Panagiotidis, P., \& Arvanitis, P. (2020). Réalité Augmentée et développement des compétences langagières à l'oral. Langues \& Cultures, 1 (IKEEART-2021-393), 99-112.

[36] Lee, K. (2012). Augmented reality in education and training. TechTrends, $56(2), 13-21$.

[37] Leonard, S. N., \& Fitzgerald, R. N. (2018). Holographic learning: A mixed reality trial of Microsoft HoloLens in an Australian secondary school. Research in Learning Technology, 26.

[38] Levy, S. (2017, October 7). Google Glass 2.0 is a startling second act. Wired. https://www.wired.com/story/google-glass-2-is-here/ . 
[39] Liu, P. H. E., \& Tsai, M. K. (2013). Using augmented-reality-based mobile learning material in EFL English composition: An exploratory case study. British Journal of Educational Technology, 44(1), E1-E4.

[40] Liu, T. Y., Tan, T. H., \& Chu, Y. L. (2007, July). 2D barcode and augmented reality supported english learning system. In 6th IEEE/ACIS International Conference on Computer and Information Science (ICIS 2007), 5-10. IEEE.

[41] Liu, T. Y., Tan, T. H., \& Chu, Y. L. (2008, December). QR code and augmented reality-supported mobile English learning system. In Workshop of Mobile Multmedia Processing, 37-52. Springer, Berlin, Heidelberg.

[42] Mahadzir, N. N., \& Phung, L. F. (2013). The use of augmented reality pop-up book to increase motivation in English language learning for national primary school. Journal of Research \& Method in Education, 1(1), 26-38.

[43] Marketwatch (2021, May 26). Online. https://on.mktw.net/3i2v3e5 .

[44] Milgram, P., \& Kishino, F. (1994). A taxonomy of mixed reality visual displays. IEICE TRANSACTIONS on Information and Systems, 77(12), 1321-1329.

[45] Núñez, M., Quirós, R., Núñez, I., Carda, J B., \& Camahort, E. (2008). Collaborative augmented reality for inorganic chemistry education. Proceedings of the 5th WSEAS/IASME International Conference on Engineering Education, 271-277.

[46] Ogata, H., Akamatsu, R., Yano, Y. (2005). TANGO: Computer Supported Vocabulary Learning with RFID tags. Journal of Japanese Society for Information and Systems in Education 22(1), 30-35.

[47] Ong, S. K., Shen, Y., Zhang, J., \& Nee, A. Y. (2011). Augmented reality in assistive technology and rehabilitation engineering. In Borko Fucht (Ed) Handbook of augmented reality, 603-630. Springer Science \& Business Media. New York.

[48] Parmaxi, A., \& Demetriou, A. A. (2020). Augmented reality in language learning: A state-of-the-art review of 2014-2019. Journal of Computer Assisted Learning, 36(6), 861-875.

[49] Parsons, D., Inkila, M., \& Lynch, J. (2019). Navigating learning worlds: Using digital tools to learn in physical and virtual spaces. Australasian Journal of Educational Technology, 35(4), 144-159.

[50] Perry, B. (2015). Gamifying French Language Learning: a case study examining a quest-based, augmented reality mobile learning-tool. ProcediaSocial and Behavioral Sciences, 174, 2308-2315.

[51] Pomerantz, J. (2018). Learning in Three Dimensions: Report on the EDUCAUSE/HP Campus of the Future Project. ECAR research report. Louisville, CO: EDUCAUSE, August 2018.

[52] Pomerantz, J. (2019). XR for Teaching and Learning: Year 2 of the EDUCAUSE/HP Campus of the Future Project. ECAR research report. Louisville, CO: EDUCAUSE, October 2019.

[53] Rafiq, K. R. M., \& Hashim, H. (2018). Augmented Reality Game (ARG), 21st century skills and ESL classroom. Journal of Educational and Learning Studies, 1(1), 29-34. 
[54] Reinders, H., \& Pegrum, M. (2016). Supporting Language Learning in the Move. SLA research and materials development for language learning, 221233.

[55] Richardson, D. (2016). Exploring the potential of a location based augmented reality game for language learning. International Journal of Game-Based Learning, 6(3), 34-49.

[56] Rzayev, R., Hartl, S., Wittmann, V., Schwind, V., \& Henze, N. (2020, September). Effects of position of real-time translation on AR glasses. In Proceedings of the Conference on Mensch und Computer, 251-257.

[57] Schrock, K (2016, July 13). Pokémon GO in the classroom. Discovery Education online. http://blog.discoveryeducation.com/blog/2016/07/13/pokemongo/

[58] Scrivner, O., Madewell, J., Buckley, C., \& Perez, N. (2016, December). Augmented reality digital technologies (ARDT) for foreign language teaching and learning. In 2016 future technologies conference (FTC), 395-398. IEEE.

[59] Seedhouse, P., Preston, A., Oliver, P., Jackson, D., Heslop, P., Balaam, M., Rafiev, A., \& Kipling, M. (2014). The European Digital Kitchen Project. Bellaterra Journal of Teaching \& Learning Language and Literature, 7, 1-16.

[60] Solak, E., \& Cakir, R. (2015). Exploring the Effect of Materials Designed with Augmented Reality on Language Learners' Vocabulary Learning. Journal of Educators Online, 12(2), 50-72.

[61] Sydorenko, T., Hellermann, J., Thorne, S. L., \& Howe, V. (2019). Mobile augmented reality and language-related episodes. TESOL Quarterly, 53(3), 712-740.

[62] Taskiran, A. (2018, June). Augmented reality games and motivation in language learning. In EdMedia+ Innovate Learning. 892-898. Association for the Advancement of Computing in Education (AACE).

[63] Thorne, S. L., \& Hellermann, J. (2017). Mobile augmented reality: Hyper contextualization and situated language usage events. Proceedings of the XVIII International CALL Conference: CALL in Context, 721-730.

[64] Vazquez, C. D., Nyati, A. A., Luh, A., Fu, M., Aikawa, T., \& Maes, P. (2017, May). Serendipitous language learning in mixed reality. In Proceedings of the 2017 CHI Conference Extended Abstracts on Human Factors in Computing Systems, 2172-2179.

[65] Wang, Y. F., Petrina, S., \& Feng, F. (2017). VILLAGE-Virtual Immersive Language Learning and Gaming Environment: Immersion and presence. British Journal of Educational Technology, 48(2), 431-450.

[66] Wu, H.-K., Lee, S. W.-Y., Chang, H.-Y., \& Liang, J.-C. (2013). Current status, opportunities and challenges of augmented reality in education. Computers \& Education, 62, 41-49.

[67] Yang, M.-T, \& Liao, W.-C. (2014). Computer-assisted culture learning in an online augmented reality environment based on free-hand gesture interaction. IEEE Transactions on Learning Technologies, 7(2), 107-117. 
[68] Yang, S., \& Mei, B. (2018). Understanding learners' use of augmented reality in language learning: insights from a case study. Journal of Education for Teaching, 44(4), 511-513.

[69] Yeh, H. C., \& Tseng, S. S. (2020). Enhancing multimodal literacy using augmented reality. Language Learning \& Technology, 24(1), 27-37.

[70] Zhang, J., Sung, Y.-T., Hou, H.-T., \& Chang, K.-E. (2014). The development and evaluation of an augmented reality-based armillary sphere for astronomical observation instruction. Computers \& Education, 73, 178-188. 